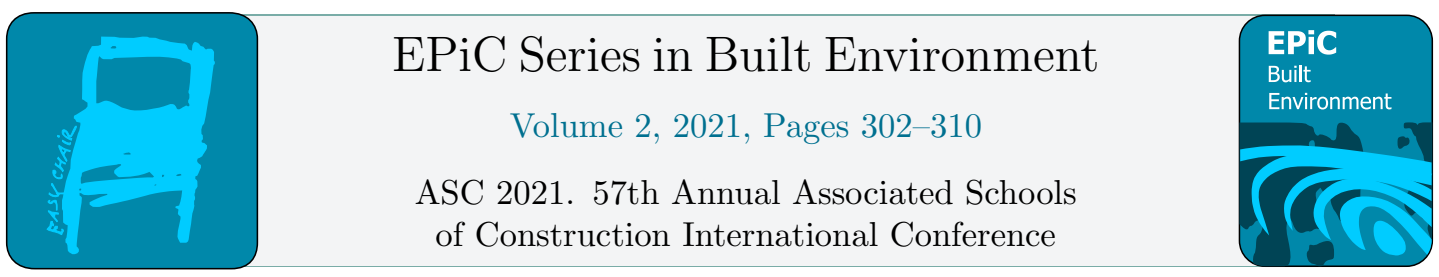

\title{
Challenges Involved in Adopting BIM on the Construction Jobsite
}

\author{
Damali Young, MS \\ Barton Malow Co. \\ Baltimore, MD
}

\author{
Kamalesh Panthi, PhD and Omar Noor, MS \\ Morgan State University \\ Baltimore, MD
}

McKinsey Global Institute (2017) in its report states that construction-related spending accounts for $13 \%$ of the world's GDP, but the sector's annual productivity has only increased $1 \%$ over the past 20 years. As with all other industries, as years pass innovation is intended to increase and introduce much higher productivity levels and safer work environments. It has been more than a decade of BIM utilization in construction jobsites. The introduction of three-dimensional modeling was supposed to serve as the turning point regarding technology in construction, but have we truly seen the effective utilization of BIM in construction process? So, what are the roadblocks to a smoother transition from paper-based 2-D to electronic 3-D Models in construction job sites? Utilizing both a questionnaire survey and an in-depth interview technique, this study explored the reasons behind the slow adoption and apprehensions in adopting 3-D Models in construction projects. Ineffective and lack of training in BIM was found to be one of the reasons for less than slower adoption of the BIM in construction job sites.

Keywords: 3-D Modeling, Design, Construction, Challenges, BIM

\section{Introduction}

With such complex equipment and highly logistic processes, one would be led to believe that the built environment employs innovation as a necessity for project success. However, the safety and productivity parameters revolving around the business have not changed as dramatically as other industries. "Much of construction has evolved at a glacial pace. Construction is among the least digitized sectors in the world, according to MGI's digitization index. In the United States, construction comes second to last, and in Europe, it is in the last position on the index. Globally, labor-productivity growth in construction has averaged only 1 percent a year over the past two decades, compared with growth of 2.8 percent for the total world economy and 3.6 percent in the case of manufacturing" (McKinsey Global Institute, 2017). A majority of the constraints that construction projects identify are cost, time, safety, and quality. Dangerous heights, toxic chemicals, and extreme temperatures limit employees as to how quickly they can work. Life safety is a topic that tends to avoid innovation because it is difficult to convince a company to leave the safety of an individual's life in the hands of artificial intelligence. While this is a logical reason to resist this technology movement, there have been a host of proven technologies that prioritize safety while increasing productivity. "The BIM coordination model enables the users to view how all the elements of the 
architectural, structural, and MEP systems have coordinated with each other in 3D space". It has been proven time and again that over $65 \%$ of human beings learn and comprehend more easily with visual components than any other forms of information distribution and construction employees are no exception. However, even with this seemingly singular notion regarding visual learning, the built environment industry seems to be behind the curve. The root of this issue can be discovered if an analysis is done on the differing demographics of those that work in the industry. According to the Bureau of Labor Statistics (BLS, 2020) data from the U.S. Department of Labor, the average age of workers in the construction industry is 42.6 . The shift to a 42.6 year average age from a 40.5 year average age happened within a 7 -year time frame in construction. By comparison, the average age for all workers in the United States increased by less than one year during the same 7-year period. Coupled with studies published that exhibit older individuals do not necessarily have a blatant dislike of technology but more feelings related to "apprehension about lack of, or lack of clarity in, instructions and support" to learn the technology, it can be deduced that construction lacks in innovation because there is a gap in the training of it.

The purpose of this study is to identify the challenges of adoption of BIM by field personnel in their day to day job activity. The majority of a design team during the preconstruction of a project has access to an accurate model but it consists mostly of architectural and landscape concerns - not as much structural or MEP systems. Besides, field personnel's access to this model is not as easily accepted as it is with architects and owners. The research questions that need to be asked are: What are the roadblocks to implementing BIM in construction jobsites? Another factor playing into the innovation-deprived industry is the generational gap within the workforce. Does this resistance to three-dimensional modeling have to do with the generation gap seen in the construction industry? The answers to these questions will provide valuable insights in providing recommendations to smooth adoption of BIM in construction field operations.

\section{Literature Review}

One of the highest standards in three-dimensional technology is BIM - Building Information Modeling. The technological factors that are affecting the use of BIM in the construction projects is the lack of BIM software packages, lack of information sharing, and lack of ability of two or more systems or components to exchange information and interpret them and then use the information (Enshassi et al., 2019). Another factor commonly identified in the literature related to barriers to BIM adoption is the socio-organizational barrier which includes important aspects such as team resistance to change, leading to generational gaps in BIM skills and understanding between young and adult practitioners (Alreshidi et al., 2018). While we see a rapid rise in the application of more collaborative tools such as BIM in the design and construction space there is a generation gap within the construction industry between those who use BIM and are exposed to the risks associated with them and those who negotiate and sign contracts. Legal teams and company boards must invest time to understand the nuances of technology such as BIM for all parties to develop rules, protocols, and contract documents that can meet the needs of an ever-evolving application of intelligent 3D Modeling across all project phases (ENR, 2019).

People's varying perspectives on the goal of BIM has also been identified as another important barrier to smoother BIM adoption. Hence, there is a need for senior management in a construction company to infuse education and training into BIM. In general, contractors need to see that BIM's potential benefits can lead to a greater context (Ibrahim et al., 2019). The shortage of skilled workers becomes an increasing challenge, and traditional training methods have disadvantages when faced with this 
challenge in the construction sector; the emergence of new educational methods, which includes the instructional video and the BIM-based learning environment, could offer some new ideas to help solve this shortage problem (Zhong, 2016). A lack of awareness about BIM technology has been an issue and a hindrance to the implementation of BIM in construction. Ern et al. (2020) used a questionnaire survey to understand the enablers and hindrances of BIM's use in construction. According to the research, cost, time, and inadequate information hinder adopting BIM in construction industry.

Acknowledging the fact that field personnel, which are comprised of the older workforce in the job site, will be the game changers in the adoption of BIM if they are convinced that BIM can enable their job and increase productivity in the job site. In this regard, an emphasis on research should be given to how this population group can be effectively trained in the adoption of new technology. Important literature outside of the construction field in this regard is by Vaportzis et al. (2017) which was conducted to identify the perception older adults have of mobile technologies. The summation of the results they received was concerning constraints such as "lack of instructions and guidance, lack of knowledge and confidence, health-related barriers, [and] cost". The basis of the conclusion was that most of these elder adults are eager and open to adopting new technologies but that their apprehension lies in the training and support aspect of it.

\section{Methodology}

During this study, both in-depth interviews and questionnaire surveys were conducted. The detailed interviews were conducted with seven individuals immersed in the world of three-dimensional technology. These professionals were selected based on convenience sampling where they were available for interviews with the researchers upon request. All of them had a considerable understanding of BIM and shared insights on the challenges related to the adoption and implementation of BIM in different representative organizations in which they worked. These interviews were guided by the following questions:

i. In your experience, what is the biggest cause of resistance to the use of 3D modeling in the field? And are there are any specific techniques you have utilized to overcome them?

ii. What were some of the greatest frustrations you faced while using 3D modeling technology? This could be technological hiccups or struggles while creating a collaborative experience with other trade models.

iii. What has your experience been, if any, with training in the use of 3D modeling in construction? If you have had training, what was the format?

iv. How comfortable/willing would you be or feel if your respective company requested that you conduct training in 3D modeling? Could you elaborate if you answered that you were not willing?

The second mode of data collection was the questionnaire survey. The questions were administered using a survey through a popular online survey website, surveymonkey.com, by sending the link to construction professionals, who were working on different construction projects in the State of Maryland and Virginia. The survey encompassed ten questions - the first two being separate from the remaining scaled questions. The participants were not asked to disclose their names but rather their position to determine any trends between differing levels of field exposure and physical job-site presence. The eight questions that required an answer based on a Likert scale of one through five 
ranging from "very uncomfortable" to "very comfortable" respectively in adopting and implementing various functions of BIM for their jobs. Both qualitative and quantitative results are provided in the next section to uncover the types of challenges that were perceived by the participants.

\section{Results and Discussions}

The results presented here are from two sources of information as outlined in the Methodology section. Results from the in-depth interviews are provided in qualitative form, whereas the results from the surveys of 42 construction professionals are provided in the form of graphs.

According to the in-depth interviews conducted with an architect, two field engineers, a virtual designer, two VDC managers, and an Associate professor, all of whom utilized BIM in their respective professions, the results provided critical information concerning the challenges of implementing BIM in construction.

According to the Architects and Virtual Design and Construction Manager, the 3D community is slowly but steadily growing. More and more architects integrate this powerful toolset in their companies every day, taking the digital representation a step further in bringing it closer to reality. The BIM aspect still has a lot of work to be done. This technology is quite far from our common, everyday construction and building, just because of people's unawareness on the job site. Online resources such as YouTube tutorials were the most useful tool in learning about 3D Modeling. On the other hand, the response provided that training was the best method in understanding the use of 3D software and the BIM technology, although the training process encountered various challenges, such as time and cost issues.

According to the findings from an interview conducted with two field engineers, getting training about 3D Modeling in construction is the best experience to gain knowledge concerning software design and apply the field knowledge with confidence. Also, the application of 3D modeling technology in the field is a challenge to many. Most field engineers learn and understand the theory of 3D Modeling but fail to apply the knowledge. On the other hand, the field engineers encounter difficulties due to a lack of knowledge and expertise concerning the software. Field engineers should have the ability and confidence to fix software issues. Additionally, field engineers face frustration for using outdated and incompatible software versions. Mostly, the new engineers find it challenging to deal with older software when using when having the knowledge and expertise of new software. The high cost of new BIM software is a challenge to most field engineers, as the most required and effective software type. Training and learning about 3D Modeling would help get new techniques to promote productivity and perfection in practical work.

An in-depth interview conducted with the Senior Project Engineer-Virtual Design and Construction, 3D modeling, and BIM technology is the most important technology in the construction industry. According to the response, some of the most important BIM software are Revit, Navisworks, Civil 3D, Sketchup, VRay, Plant 3D. In addition, for 3D Modeling the biggest obstacle to being used in the field is technical difficulty and time needed to create a 3D model from zero. Also, the frustration while using 3D Modeling is that 3D modeling software is not universal. Because there are many types of BIM software and some of the BIM software's formats are not eligible to be converted to be used in another software. 
According to the in-depth interview conducted with the Senior Virtual Design and Construction Managers one of the hindrances of implementing 3D Modeling in the field is the mindset of upper management. In their opinion, they have been using their older methods and techniques for ages, and it has yielded them good results. They fail to realize that innovation in the construction industry and the latest tools and technology make it so much easier to work with. Another problem in implementing 3D Modeling in the construction industry is interoperability, or rather the lack of interoperability. Teaching 3D Modeling can be challenging as it requires resources and allocated time just for learning. There should be a focus on teaching young minds about the latest methods and technologies.

According to the in-depth interview conducted with the Associate professor who has experience in using BIM, one of the construction industry's resistances to utilize 3D models is that the models cannot be very handy on the construction site compared to the "issued for construction" drawing sheets. Moreover, the 3D model is acceptable in some parts of the world as a submission model; however, many countries still have to submit the traditional structural drawings to approval departments. One of the hindrances of using 3D modeling technology is the big size of the BIM models causing slow computers while using the software and increasing the time of delivering the project or the task.

Other insights gained from the in-depth interviews with various experts in BIM are described herein. In general, they expressed their two major frustrations being coordination between designers and fabricators as well as the concept that "The hardware needs to catch up with the software." Regarding integrating field personnel into the technological loop, the field engineer explains how "In an ideal world, you can have the entire building, perfect renderings, perfect detail, all in one file, but only supercomputers can open it. Tablets and iPads can only open segmented versions of the model." The theory of BIM's benefits become neutralized if the only individuals that can open it are designers and virtual design construction engineers and not those actually building the project.

The next set of results presented below are from the questionnaire survey sent to more than 100 construction professionals. There were 42 responses received. The results are presented in graphical format for easy understanding and processing. Based on the information obtained below, it can be determined from Figure 1 that the vast majority (94\%) of participants used BIM in their job at least once a day. It can also be determined from Figure 2 that a substantial majority of respondents (78\%) were introduced to three-dimensional modeling within two years of their career. What this tells about the respondents is that they are relatively newcomers in the industry with less construction experience. This also reveals another fact that there wasn't a single professional that was not introduced to this technology before ten years of operating in the design and construction industry.

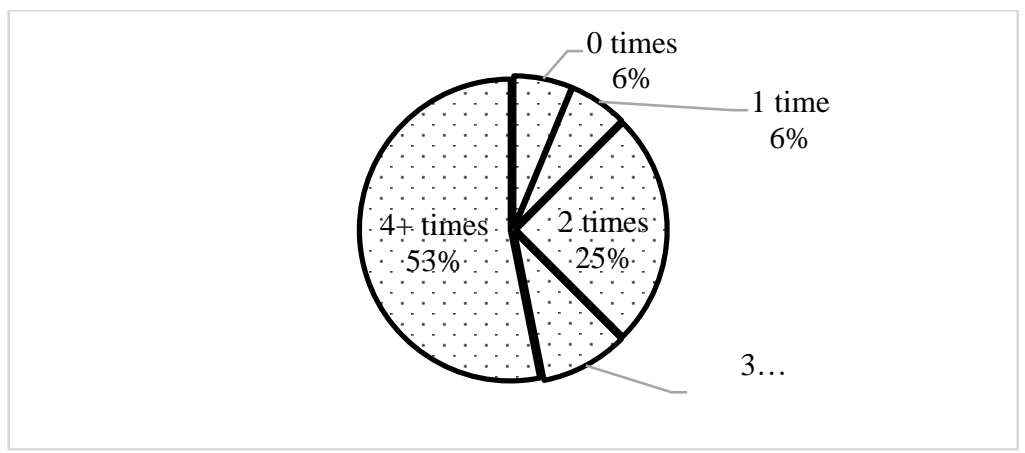

Figure 1. Frequency of BIM Usage in a Day 


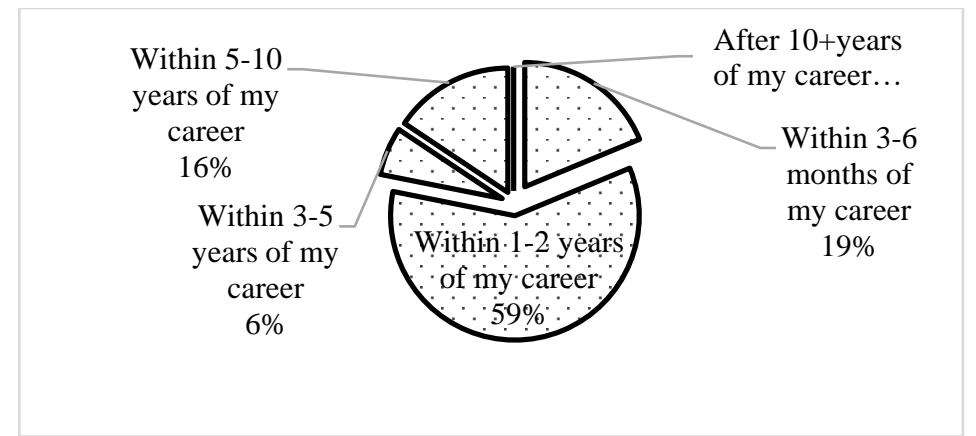

Figure 2. Year in Career When 3D Modeling was Introduced

The next set of questions all relate to the basic understanding and usage of BIM by professionals for more general basic functions such as dimensioning and measurement, viewing and understanding architectural details, etc. that were usually performed with the aid of 2D printed drawings. When respondents were asked to rate their comfortability level in each of those above basic functions, they indicated a relatively higher comfortability level. The combined comfortability level in performing these basic functions as indicated in Figure 3 to Figure 6 lies somewhere close to "comfortable" with a mean rating of 4.1 .

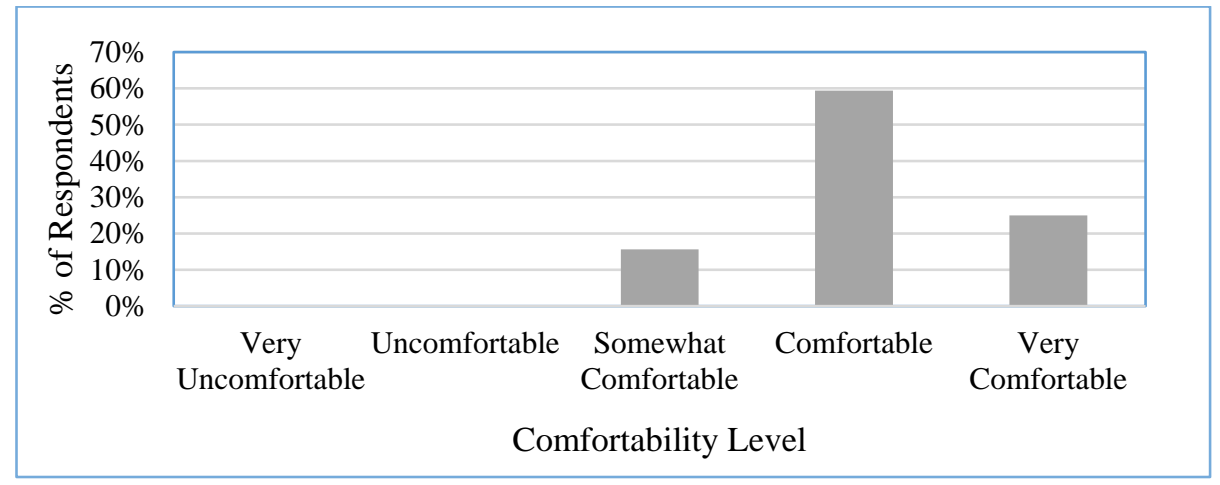

Figure 3. Comfortability in Using 3D for Dimensioning/Measurement

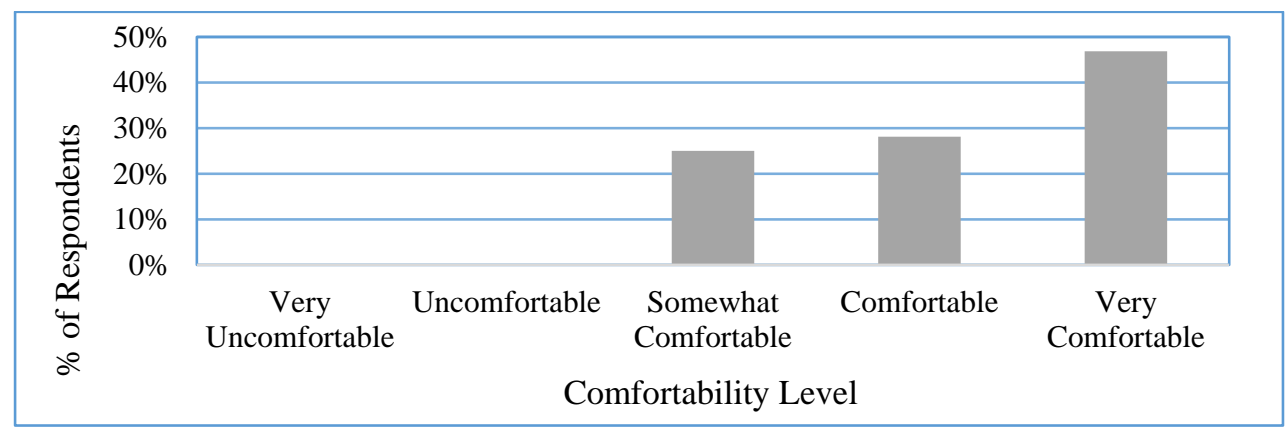

Figure 4. Comfortability in Using 3D to Understand Architectural Details 


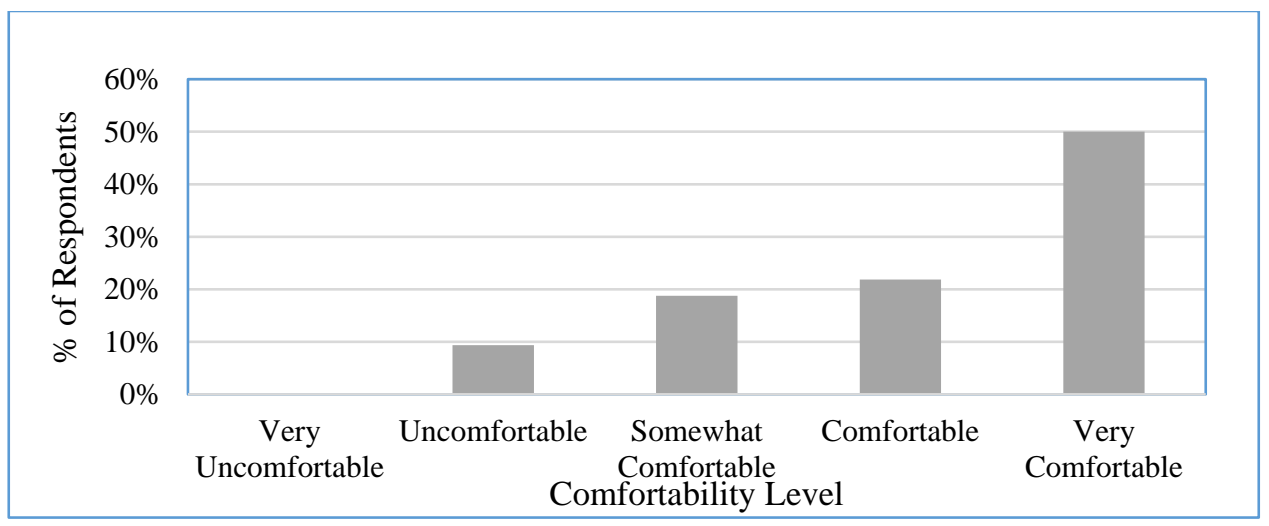

Figure 5. Comfortability in Introducing 3D Modeling on a Project

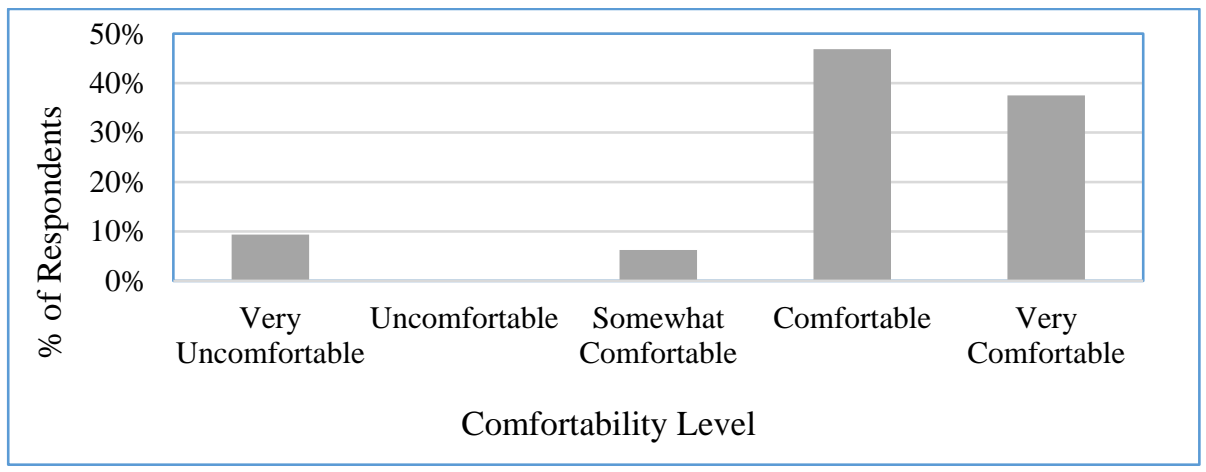

Figure 6. Comfortability in Conducting a Meeting with a 3D Model as the Main Source of Information

The next set of questions aimed at measuring the level of comfortability of more specialized BIM functions such as clash detection and for resolving construction disputes by utilizing a 3D model and its simulations. This requires a higher level and a more specialized BIM skill. Understandably, the comfortability level of performing these more specialized functions related to BIM was at an average level of comfortability with the combined mean comfortability level of 3.8 . This information can be visualized in Figure 7 to Figure 8.

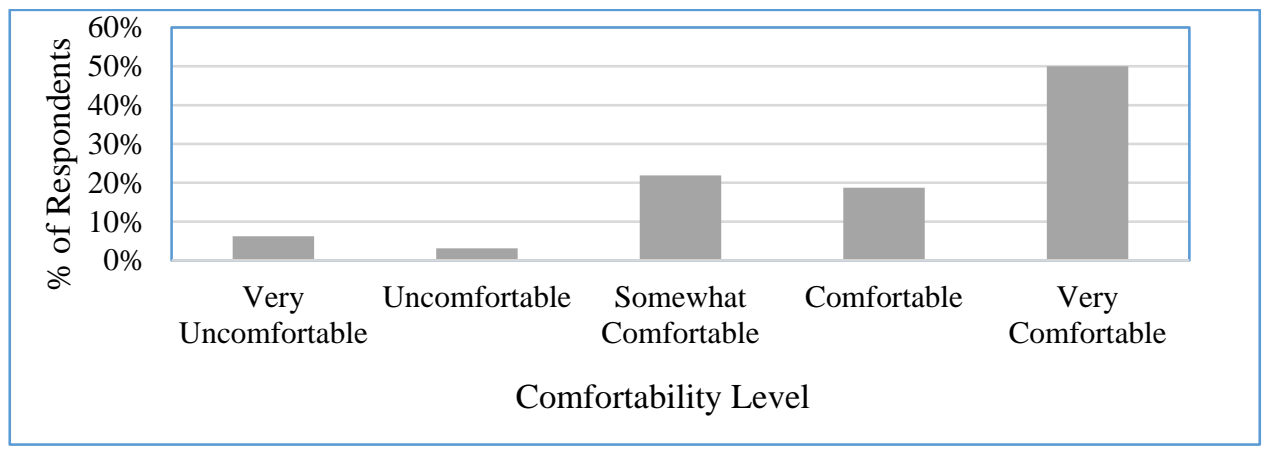

Figure 7. Comfortability in Utilizing a 3D Modeling Tool for Clash Detection \& Constructability 


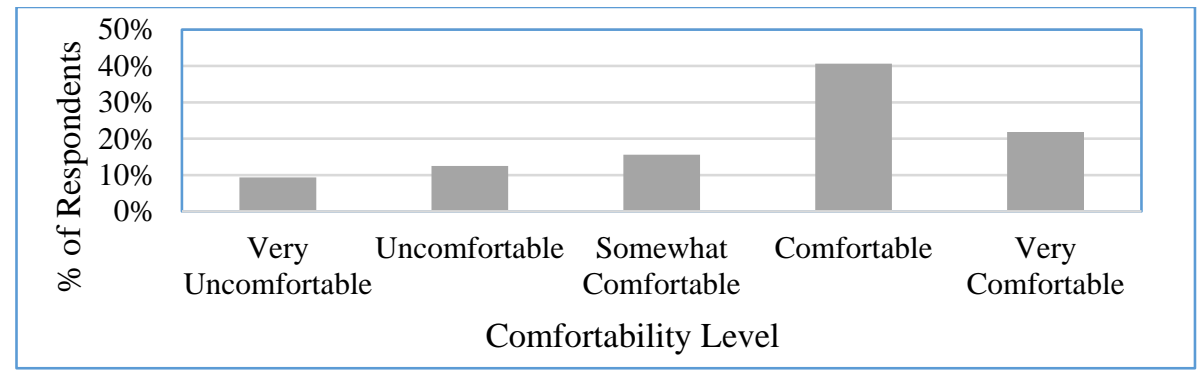

Figure 8. Comfortability in Using a Constructed 3D Model in Contractual Disputes

The last set of questions in the questionnaire survey pertained to the comfortability level in conducting BIM-related training to their peer as this is the best enabler to widespread adoption of BIM in any organization. The combined mean comfortability level of conducting BIM-related training in their specific organization was 3.4. This rating indicates that the respondents had a relatively lower comfortability level in training their peers compared to other BIM related functions. This is shown in Figure 9 and Figure 10.

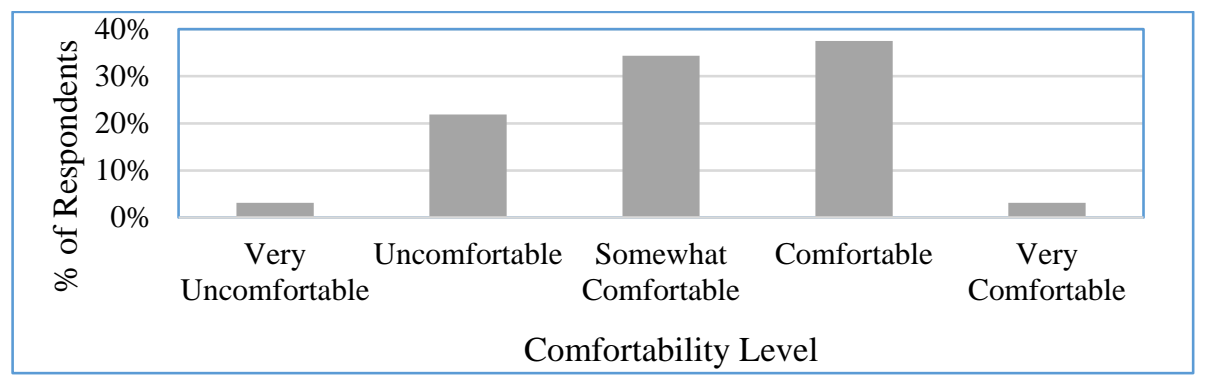

Figure 9. Comfortability in Explaining the Tools of a 3D Modeling Tool to Other Individuals

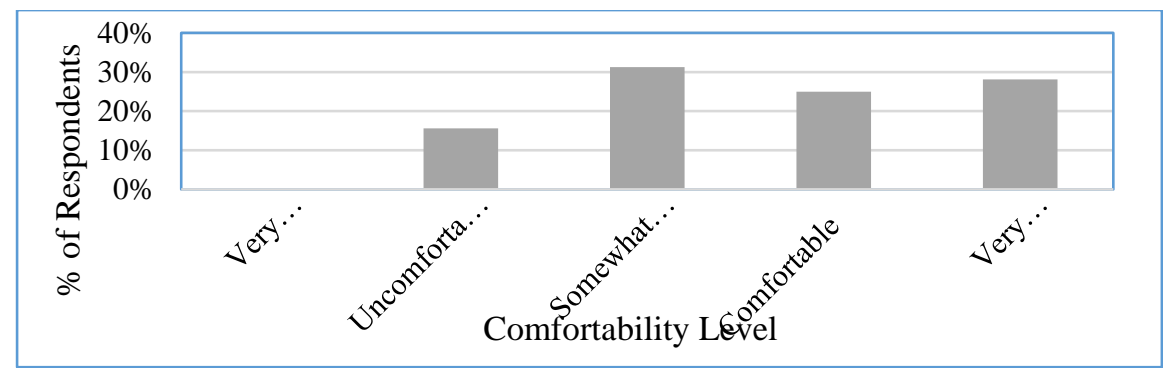

Figure 10. Comfortability in Conducting a Training of Basic Navigation for a 3D Modeling Tool

\section{Conclusion and Recommendations}

The conclusion of the research data gathered throughout this work ranges between a few theories. One of them is that there is, in fact, a blatant resistance in the construction industry to this threedimensional modeling movement. The research questions raised throughout this process were how more appropriate and effective training methods can be implemented, a question as to whether the generation gap plays a role in this technological resistance, and what the existing products are in this 
realm of virtual design and construction. As it has been laid out here, generalized educational sessions in large settings are not the most optimum training methods for this information. Allowing field personnel to learn specific features, on-site, in real-time proves to be the most effective. Also, ensuring that these individuals are then placed on projects that plan on implementing BIM emphasizes the knowledge they retained. Regarding the existing resistance to integrating this technology, the aging construction workforce may not be as strong as a contributor as perceived. While older adults do struggle to adapt to technological advances, it is not necessarily due to personal adverse beliefs. Rather, that they do not feel accepted into the increasingly automated world. Any lack of conception in association with BIM technologies stems from insufficient instruction and affects all ages in the construction industry. These technologies are not scarce - a surplus of software, platforms, and licenses exist but are not being exercised to their greatest capacity.

If construction as a community does not want to be left behind and be considered an outdated field, giving seriously allotted resources to procure, train, and implement three-dimensional modeling will be essential. While many of the environmental hazards and risks still exist no matter the innovation, all categories of firms will be able to better mitigate those occurrences with highly accurate, multidimensional models to work with. As with the majority of business units, people are at the core of construction's success. As with the study presented in the above sections, when the time is presented to train those that build in the technology with a personal aspect to it, the resistance is negligible. Building Information Modeling, if implemented aggressively and accurately, can severely disrupt the stagnation of this industry. Education and training will be the construction's empowerment.

\section{References}

Alreshidi, Eissa; Mourshed, Monjur; Rezgui, Yacine (2018): Requirements for cloud-based BIM governance solutions to facilitate team collaboration in construction projects. In Requirements Eng 23 (1), pp. 1-31. DOI: 10.1007/s00766-016-0254-6.

Bureau of Labor Statistics, BLS (2020). Labor Force Statistics from the Current Population Survey. https://www.bls.gov/cps/cpsaat18b.htm

Doumbouya, L., Gao, G., \& Guan, C. (2016). Adoption of the Building Information Modeling (BIM) for construction project effectiveness: The review of BIM benefits. American Journal of Civil Engineering and Architecture, 4(3), 74-79.ENR: Engineering News-Record (2019).

Collaboration, Contracts and Fair Resolution Industry leaders talk trends. by Michael B. Bomba, Esq., Director and Counsel AIA. Vol. 283 Issue 5, p35-37. 3p., (2019)

Enshassi, M. A., Al Hallaq, K. A., \& Tayeh, B. A. (2019). Limitation Factors of Building Information Modeling (BIM) Implementation. The Open Construction \& Building Technology Journal, 13(1), 189-196. https://doi.org/10.2174/1874836801913010189

Ern, P. A. S., Ooi, Y. Y., \& Al-Ashmori, Y. Y. (2020). Comparative Study on the Perspective towards the Benefits and Hindrances of Implementing Building Information Modelling (BIM). International Journal of Sustainable Construction Engineering and Technology, 11(1), 194-205.

Ibrahim, H. S., Hashim, N., \& Ahmad Jamal, K. A. (2019). The Potential Benefits of Building Information Modelling (BIM) in Construction Industry. IOP Conference Series: Earth and Environmental Science, 385, 12047. https://doi.org/10.1088/1755-1315/385/1/012047

McKinsey Global Institute (2017). "Reinventing Construction: A Route to Higher Productivity." https://www.modular.org/HtmlPage.aspx?name=MA-feature-higher-prod

Vaportzis, E., Giatsi Clausen, M., \& Gow, A. J. (2017). Older Adults Perceptions of Technology and Barriers to Interacting with Tablet Computers: A Focus Group Study. Frontiers in Psychology, 8 .

Zhong, Y. (2016). BIM-based Construction Training Program for Low-skilled Workforce: Visualization and Development of Equipment, Tools and Procedures for Construction Tasks. 